\title{
AN ANATOMICAL STUDY OF FORAMEN OVALE WITH CLINICAL
} IMPLICATIONS

\section{Das Saurjyaranjan ${ }^{1}$, Champatyray Sreepreeti *2, Nayak Gyanaranjan ${ }^{1}$.}

${ }^{1}$ Department of Anatomy, IMS and SUM Hospital, Siksha 'O' Anusandhan,K8,Kalinga Nagar, Bhubaneswar, India.

*2 Department of Oral pathology and Microbiology, Institute of Dental Science, Siksha 'O' Anusandhan,K8,Kalinga Nagar, Bhubaneswar, India.

\section{ABSTRACT}

Introduction: Foramen ovale is one of the important foramen found in the greater wing of the sphenoid bone. The structures passing through the foramen are mandibular nerve, accessory meningeal artery, lesser petrosal nerve and emissary vein.The shape of the foramen is oval in shape. An anatomical study of the foramen was done to note the size and shape of the foramen ovale.

Material and methods: The study was done 50 human dry skull of unknown sex and age. The anterior posterior diameter and transverse diameter was measured by a divider and meter scale.

Result: The maximum anterior posterior diameter was found to $9.8 \mathrm{~mm}$ on right side and $9.6 \mathrm{~mm}$ on left side. The maximum transverse diameter was found to be $4.6 \mathrm{~mm}$ on right side and $4.7 \mathrm{~mm}$ on left side. The mean anterior posterior diameter on right is $7.11 \pm 1.688$ and on the left was $6.53 \pm 1.333$. The mean transverse diameter of the foramen on right was $3.148 \pm 0.686$ and on the left was $3.2 \pm 0.678$. The foramen ovale was found to be symmetric in $14 \%$ of the skulls. The shape of the foramen was found to be oval in $70 \%$, almond in $18 \%$, rounded in $8 \%$ and triangular in $4 \%$.

Conclusion: The variation of the foramen ovale has a great clinical and surgical significance to the neuro surgeons and physicians before exploring the middle cranial fossa. It will help in diagnosis and treatment of various vascular tumors and aneurysms.

KEY WORDS: Foramen Ovale, Sphenoid Bone, Trigeminal Neuralgia, Skull.

Address for Correspondence: Dr Sreepreeti Champatyray, Department of Oral pathology and Microbiology, Institute of dental science, Siksha 'O' Anusandhan, K8, Kalinga Nagar, Bhubaneswar, India.Phone-9439850143 E-Mail: sreepreetichampatyray@gmail.com

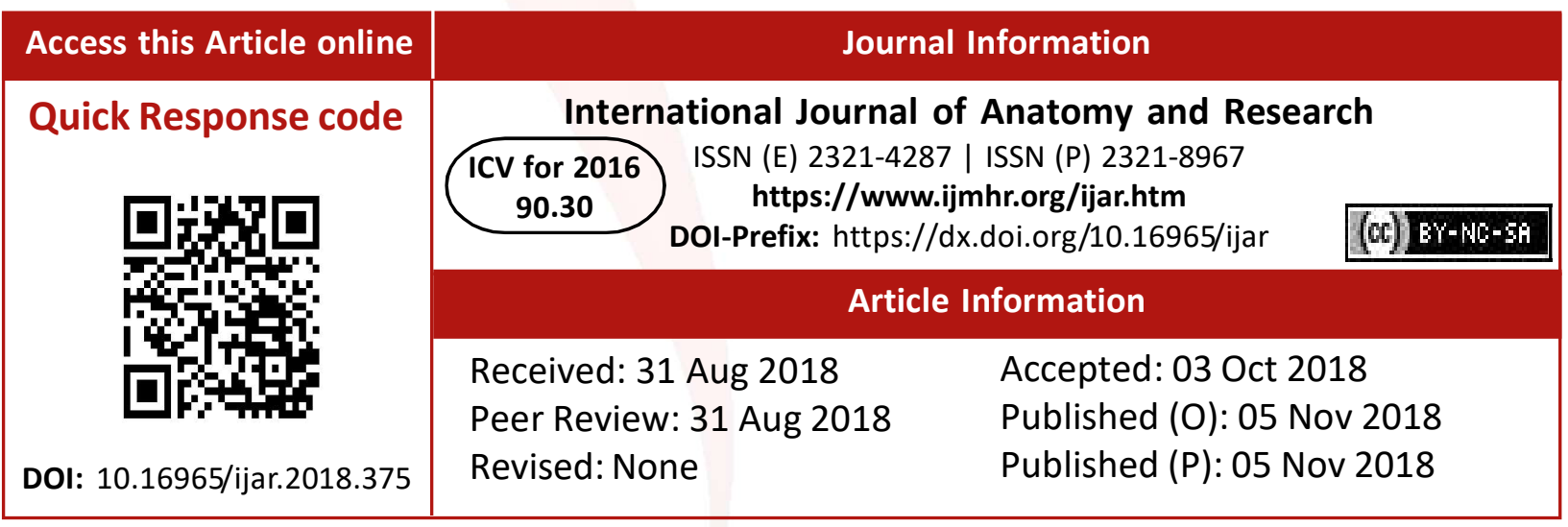

\section{INTRODUCTION}

The base of the skull has several foramina out of which the foramen ovale is one of the important foramen present in the greater wing of sphenoid bone [1,2]. It is present medial to foramen spinosum. It connects the infra temporal fossa with the middle carnial fossa [3]. The structures passing through it are mandibular division of trigeminal nerve, accessory meningeal artery, lesser petrosal nerve, emissary veins which connects the pterygoid venous plexus in the infra temporal fossa to the cavernous sinus [4]. The longitudinal axis of the foramen lies laterally and ventrally to the direction of the mandibular nerve. The study of the foramen is of great interest to the anatomist, anthropologist, 
radiologist and clinicians because of the greater clinical and radiographic significance.

The foramen ovale is used for different surgical and diagnostic procedures like fine needle aspiration via transfacial approach, to dignose squamous cell carcinoma, meningioma, and the spread of the tumors $[5,6]$. It is also used for electroencephalographic analysis of of the seizure for patients, trigeminally rhizotomy for trigeminal neuralgia by percutaneous approach [7]. The adminstration of anesthesia via mandibular nerve can be done after a thorough knowledge of the morphometry of the formamen ovale [8]. The percutaneous biopsy of the cavernous sinus can be done through foramen ovale [9]. The foramen ovale is absent in the class reptiles and is acquired in mammals during the process of evolution. When the mandibular nerve is entrapped in the foramen ovale it causes trigeminal neuralgia. Studies have shown that foramen ovale on the right side is narrower than the left this may be the cause trigeminal neuralgia on the right side [10]. The otic ganglian lies immediately below the foramen in the infratemporal fossa [11]. The naso pharyngeal carcinoma may spread into carnial cavity through the foramen ovale [12].

The sphenoid bone develops by both intra membranous and endochondral ossification, the body of the sphenoid known as basisphenoid which develops from both presphenoid and postsphenoid center. The post sphenoid give rise to greater wing of sphenoid. The mandibular nerve surrounded by cartilage to form the foramen ovale [13]. The present study was done on different diameters of the foramen such as length, width, shape of the foramen which will help the neuro surgeons for treating neurological diseases.

Our present study was conducted to define anatomical variations in foramen ovale may be important for forensic, anthropological and surgical purpose and this study aims to highlight such [8].

\section{MATERIALS AND METHODS}

The study was carried out on 100 foramen ovale using 50 dry adult human shpenoid bones of unknown age and sex from the department of Anatomy, IMS \& SUM Hospital, Odisha.
The greater wing of sphenoid bone was examined fior the presence of foramen ovale. The skull which were damaged or fractured around the foramen was excluded from the study. Measurments of the foramen ovale were taken both right and left side by using divider and meter scale. The parameters which were study are:

1. Shape of the foramen

2. Presence of any bony projections like a tubercule, spine, septae or bone plate.

3. Anterior and posterior (Length) and transverse (width) diameter of the foramen were measured.

The measurements were recorded in millimeters then the data often was statistically analyzed.

\section{RESULTS}

The foramen ovale was present bilaterally in all skulls. The study was done on total of 100 foramen ovale in 50 dry adults skulls. The maximum and minimum anterior posterior diameter (length) of the foramen ovale on right and left was $9.8 \mathrm{~mm}, 4.3 \mathrm{~mm}$ and $9.6 \mathrm{~mm}, 3.2 \mathrm{~mm}$ respectively.

The maximum and minimum transverse diameter (width) of foramen ovale on the right and left side was $4.6 \mathrm{~mm}, 2.1 \mathrm{~mm}$ and $4.7 \mathrm{~mm}$, $2.2 \mathrm{~mm}$ respectively.

The mean anterior posterior diameter (length) of foramen ovale on right is $7.11 \pm 1.688$ and on the left was $6.53 \pm 1.333$.

Mean transverse diameters (width) of foramen ovale on right was $3.148 \pm 0.686$ and on the left was $3.2 \pm 0.678$. as shown in Table 1.The foramen ovale was found to be symmetric in $14 \%$ of the skulls.

Table 1: The mean anterior posterior and transverse diameter of the foramen on right and left.

\begin{tabular}{|c|c|c|c|c|}
\hline $\begin{array}{c}\text { Dimensions of } \\
\text { values }\end{array}$ & $\begin{array}{c}\text { Foramen } \\
\text { Ovale length } \\
\text { (Left) } \mathrm{mm}\end{array}$ & $\begin{array}{c}\text { Foramen } \\
\text { Ovale length } \\
\text { (Right) } \mathrm{mm}\end{array}$ & $\begin{array}{c}\text { Foramen } \\
\text { Ovale Width } \\
\text { (Left) } \mathrm{mm}\end{array}$ & $\begin{array}{c}\text { Foramen } \\
\text { Ovale Width } \\
\text { (Right) } \mathrm{mm}\end{array}$ \\
\hline Maximum & 9.6 & 9.8 & 4.7 & 4.6 \\
\hline Minimum & 3.2 & 4.3 & 2.2 & 2.1 \\
\hline Mean & 6.53 & 7.11 & 3.2 & 3.148 \\
\hline SD & 1.333 & 1.688 & 0.678 & 0.686 \\
\hline P-Value & \multicolumn{2}{|c|}{$\geq 0.05$} & \multicolumn{3}{c|}{$\geq 0.05$} \\
\hline
\end{tabular}

The percentage of variation in shape of foramen ovale was determined, the shape of the foramen was found to be oval in 70\%, almond in $18 \%$ rounded in $8 \%$ and triangular in $4 \%$ as 
shown in Table 2. The outline of the foramen was not smooth and regular in all cases.

Table 2: The percentage of variation in shape of foramen ovale.

\begin{tabular}{|c|c|c|c|}
\hline Shape & Right & Left & Total \\
\hline Oval & 32 & 38 & 70 \\
\hline Almond & 10 & 8 & 18 \\
\hline Round & 4 & 4 & 8 \\
\hline Triangular & 2 & 2 & 4 \\
\hline
\end{tabular}

Fig. 1: Arrow showing a tubercule in the foramen.

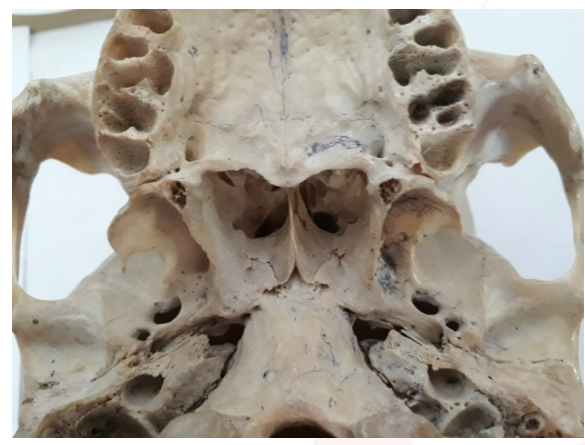

Fig. 2: Arrow showing a septa in the foramen ovale.

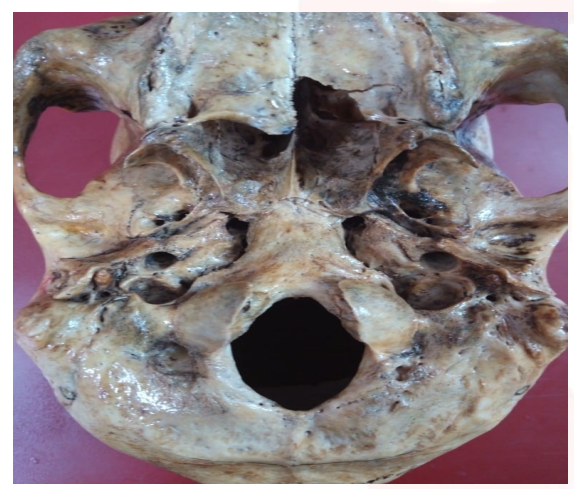

Fig. 3: Showing asymmetry of foramen ovale.

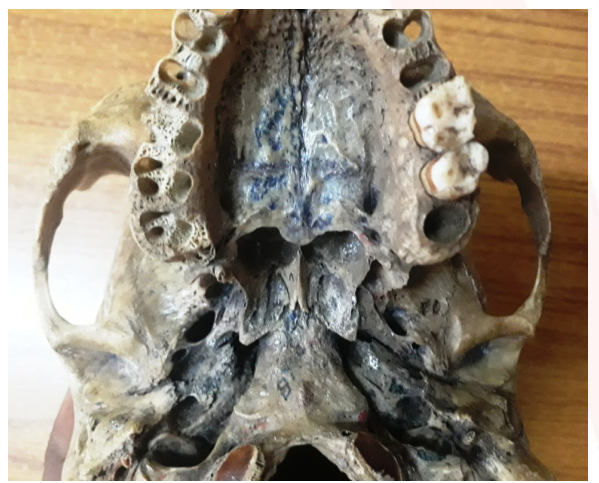

Fig. 4: Arrow showing triangular shape foramen with tubercule.

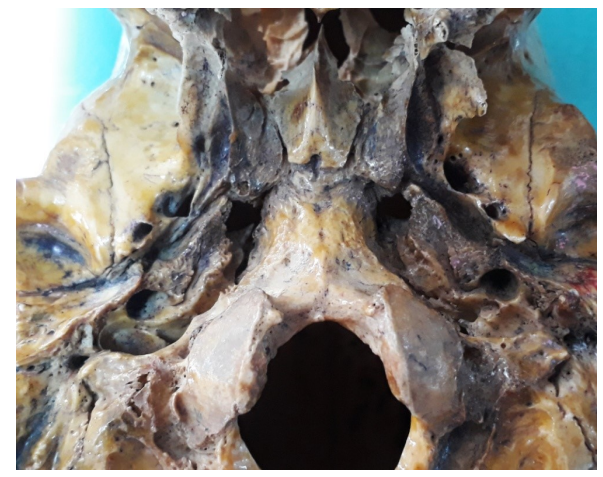

\section{DISCUSSION}

The variation of different foramina in their number, size, shape and location are due to the developmental process during evolution. It is of high clinical significance due to the neuro vascular structure passing through the narrow foramen. When there is any trauma or space occupying lesion, it results in compressive force and many clinical manifestations. Therefore a good knowledge of the variations in the foramina can guide the neuro surgeons while performing surgical operations in that area. In seventh month of intra uterine life, perfect ring shaped formation of the foramen ovale was observed and in three years after birth and the ossification takes place around the large trunks of mandibular nerve[14]. During the developmental process of foramen ovale first appearance and its ring formation bony outgrowth of the foramen ovale like spines, spur, tubercle, bony plate etc indicate bony over growth.

In a study conducted in china, $100 \%$ success rate was achieved when FO was punctured in TN radiofrequency ablation under the guidance of $X$-ray real time imaging [15]. Moreover electroencephalographic analysis of seizure by electrode placed at FO provided good neurophysiological information in candidates for selective amygdalo-hippocampectomy [16].

Bony outgrowths are found in the form a spine $\&$ bony plate arising from the margins of foramen ovale. In one skull the foramen was divided into two halves by a bony septum. Similar findings have been reported by other studies [17] It is claimed that these osseous deformities indicate bony outgrowth during the process of development[18].

Out of 100 foramina, 10 showed the presence of bony spine and bony tubercule in 4 cases. In our study the duplication of foramen was seen in the right side. Ray $B$ etal also observerbed the presence of bony spur that divided the foramen in to two separate compartments[19]. Reymopnd etal found $4.5 \%$ case in which the foramen divided into 2 to 3 compartments[6].

In the present study, the mean anterior posterior diameter (length) of foramen ovale on right is $7.11 \pm 1.688$ and on the left was $6.53 \pm 1.333$. Mean transverse diameters (width) of foramen 
ovale on right was $3.148 \pm 0.686$ and on the left was $3.2 \pm 0.678$. The foramen ovale was found to be symmetric in $14 \%$ of the skulls. The anteroposterior diameters of right foramen ovale were longer than on left side, but this variation was not statistically significant $(p>0.05)$. The transverse diameters of right and left foramen ovale was also not statistically significant ( $p>0.05)$. The present study is similar with the study done by Gupta $\mathrm{N}$ etal on 70 foramen ovale in 35 dry adult skulls. In their study the mean length of foramen ovale was $7.228 \pm 1.39 \mathrm{~mm}$ on right side and $6.48 \pm 1.131 \mathrm{~mm}$ on left side. In right side mean width was $3.57 \pm 0.70 \mathrm{~mm}$ and on left side, mean width was $3.50 \pm 0.75 \mathrm{~mm}$. The difference between the mean values of the length and width of the right and left foramen ovale was not that significant[20].

In this study the maximum and minimum length of foramen ovale on the right and left side was $10 \mathrm{~mm}, 4.4 \mathrm{~mm}$ and $9.8 \mathrm{~mm}, 3.4 \mathrm{~mm}$ respectively. This value falls in similar with the value obtained by Arun in Nepal, in which the maximum length of foramen ovale was $9.8 \mathrm{~mm}$ and minimum length was $2.9 \mathrm{~mm}$ [21].

Maximum width on right side was $5 \mathrm{~mm}$ and on left side was $4.9 \mathrm{~mm}$, while the minimum width on right side was $2.5 \mathrm{~mm}$ and on left side was $2.7 \mathrm{~mm}$. In Lang J study the average width was $3.7 \mathrm{~mm}$ [22]This results were correlating with Biswabina Ray et al, they reported the, maximum width of foramen ovale was $5 \mathrm{~mm}$ on both right and left side, while minimum width was 1 $\mathrm{mm}$ on right side and $2.2 \mathrm{~mm}$ on left side [6].

In the present study the percentage of variation in shape of foramen ovale was determined, the shape of the foramen was found to be oval in $70 \%$, almond in $18 \%$ rounded in $8 \%$ and triangular in $4 \%$. This results are in agreement with the study done by Wadhwa et al in which the percentage of shape of foramen is oval in $70 \%$, almond shaped in $15 \%$ and round in $10 \%$ and triangular like in $5 \%$ [23]. The most effective surgical treatment for trigeminal neuralgia is microvascular decompression[24].

Microvascular decompression is generally performed when the patient is healthy and relatively young[25].

Meckel's Cave can be accessed percutaneously through foramen ovale[26].

Percutaneous biopsy of lesions of cavernous sinus can be approached through foramen ovale which is minimally invasive procedure as compared to open biopsy through craniotomy [27].

\section{CONCLUSION}

Anatomical knowledge of the foramen ovale will help the neurosurgeons while exploring the middle cranial fossa. The position and location of foramen ovale is important in many diagnostic procedures. It will help in percutaneous biopsy of the cavernous sinus tumours, CT guided FNAC for diagnosis of meningioma, and squamous cell carcinoma. In trigeminal rhizotomy the mandibular nerve is the target, so this study will help in the treatment of trigeminal neuralgia.

The exact location of foramen will help the neurosurgeons and anesthesiologist to give anesthesia to the mandibular nerve for the treatment of trigeminal neuralgia.

Though the statistically analysis shows that the morphometric measurements are not significant but there is variation in the measurements of both right and left foramen.

So any abnormality in the morphology of foramen ovale may lead to several complications, so a prior knowledge about the foramen is needed by the anesthesiologist and neurosurgeons before proceeding for any intervention.

\section{Conflicts of Interests: None}

\section{REFERENCES}

[1]. Stozitzky N. \& RUEDA-ESTEBAN R. Morphometric study of five constant skull base foramina in the muisca population of the tibanica anthropological collection of the universidad de losandes. Int. J. Morphol. 2016;34(4):1313-1317.

[2]. Standring, S. Middle cranial fossa. In: Gray's anatomy. 40th Ed. Elsevier Churchill Livingstone, New York, 2008. pp.418.

[3]. Reymond J, Charuta A, Wysocki J. The morphology and morphometry of the foramina of the greater wing of the human sphenoid bone. Folia Morphologica: 2005;64(3):188-93.

[4]. Khairnar K. B. and BhusariP. A. An Anatomical Study on the Foramen Ovale and the Foramen Spinosum. J ClinDiagn Res. 2013;7(3): 427-429. 
[5]. Barakos JA, DillonWP. Lesions of the foramen ovale: CT-guided fine-needle aspiration. Radiology 1992;182: 573-575.

[6]. Biswabina Ray, Nirupma Gupta, Supriya Ghose,Anatomic variations of foramen ovale. Kathmandu University Medical Journal. 2005;3(9):64-68.

[7]. Gusmao S, Oliveira M, Tazinaffo U, Honey CR. Percutaneous trigeminal nerve radiofrequency rhizotomy guided by computerized tomography fluoroscopy: Technical note. J Neurosurg.2003;99:785-786.

[8]. Abd Latiff $A$ et al. The accessory foramen ovale of the skull: an osteological study. Clin Ter: 2009;160(4) :291-3.

[9]. Yi W, Ohman K, Brannstrom T, Bergenheim AT. Percutaneous biopsy of cavernous sinus tumour via the foramen ovale. Acta Neurochir (Wien): 2009;151(4):401-7.

[10]. Liu P, Zhong W, Liao C, Liu M, Zhang W. Narrow Foramen Ovale and Rotundum: A Role in the Etiology of Trigeminal Neuralgia. J Craniofac Surg. 2016; 27(8):2168-2170.

[11]. Sepahdari AR1, Mong S. Skull base CT: normative values for size and symmetry of the facial nerve canal, foramen ovale, pterygoid canal, and foramen rotundum. SurgRadiol Anat. 2013;35(1):19-24.

[12]. Srimani $P$ et al. Foramina in Alisphenoid - An Observational Study on Their Osseo-Morphology and Morphometry. International Journal of Anatomy, Radiology and Surgery, 2014;3(1):1-6.

[13]. John D A, Thenmozhi. Anatomical Variations of Foramen ovale J. Pharm. Sci. \& Res. 2015; 7(6):327329.

[14]. Yanagi S: Developmental studies on the foramen rotundum, foramen ovale and foramen spinosum of the human sphenoid bone. The Hokkaido Journal of Medical Science 1987;62(3): 485-496.

[15]. He YQ, He S, Shen. Application of a new method of revealing foramen ovale under X-ray in radiofrequency ablation in the treatment of trigeminal neuralgia. Br J Neurosurg. 2011;25(6):674-6.

[16]. Wieser HG, Siegel AM. Analysis of foramen ovale electrode-recorded seizures and correlation with outcome following amygdalohippocampectomy. Epilepsia 1991; 32:838-50.
[17]. Karan BK, Surekha DJ, Umarji BN, Patil RJ, Ambali MP. Foramen ovale and foramen spinosum: a morphometric study. Anatomica Karnataka. 2012; 6(3): 68-72.

[18]. Khan AA, Asari MA, Hassan A. Anatomic variants of foramen ovale and spinosum in human skulls. Int. J. Morphol. 2012;30(2):445-449.

[19]. Reymond J, Charuta A, Wysocki J. The morphology and morphometry of the foramina of the greater wing of the human sphenoid bone. Folia Morphologica: 2005;64(3):188-93.

[20]. Gupta N, Rai AL. Foramen ovale-morphometry and its surgical importance. Innovative Journal of Medical and Health Science: 2013;3(1):4-6.

[21]. Arun SK: Some observations of the foramina ovale and spinosum of human sphenoid bone. J Anat Soc India 2006;55(1):100-101.

[22]. Lang J, Maier R, Schafhauser O. Postnatal enlargement of the foramina rotundum, ovale et spinosum and their topographical changes. Anatomischer Anzeiger. 1984;156 (5):351-387.

[23]. Wadhwa A, Shrama M and Kaur P: Anatomical variations of foramen ovale- clinical implications. Int. J. Basic and applied Med Sci. 2012 Sept-Dec;2(3): 214.

[24]. Ritter PM, Friedman WA, Bhasin RR. J Neurosci Nurs. 2009 Aug;41(4):211-14.

[25]. Toda K. Operative treatment of trigeminal neuralgia: review of current techniques. Oral Surg Oral Med Oral Pathol Oral Radiol Endod. 2008 Dec;106(6):788-05.

[26]. Alvernia JE, Sindou MP, Dang ND, Maley JH, Mertens P. Percutaneous approach to the foramen ovale: an anatomical study of the extracranial trajectory with the incorrect trajectories to be avoided. Acta Neurochir (Wien). 2010 Jun;152(6): 1043-53.
How to cite this article:
Das Saurjyaranjan, Champatyray Sreepreeti, Nayak Gyanaranjan.
AN ANATOMICAL STUDY OF FORAMEN OVALE WITH CLINICAL
IMPLICATIONS. Int J Anat Res 2018;6(4.2):5921-5925. DOI:
10.16965/ijar.2018.375 